Dicle University Journal of Engineering (DUJE)

web: http://dergipark.gov.tr/dumf

Araștırma Makalesi / Research Article

\title{
Kafes yapıların JAYA algoritmasıyla doğal frekans sınırlayıcıları altında optimum tasarımı
}

\section{JAYA algorithm for optimum design of truss structures under natural frequency constraints}

\section{S. Özgür Değertekin ${ }^{1 *}$, Gülay Yalçin Bayar ${ }^{2}$}

${ }^{1}$ Dicle Üniversitesi, İnşaat Mühendisliği Bölümü, Diyarbakır, sozgurd@ gmail.com, ORCID ID: 0000-0001-8885-6468

${ }^{2}$ Dicle Üniversitesi, İnşaat Mühendisliği Bölümü, Diyarbakır, gybayar@dicle.edu.tr, ORCID ID: 0000-0002-7575-8559

\begin{tabular}{l} 
MAKALE BİLGİLERİ \\
\hline Makale geçmişi: \\
Geliş: 18 Nisan 2020 \\
Düzeltme: 8 Mayıs 2020 \\
Kabul: 15 Mayıs 2020 \\
\hline Anahtar kelimeler: \\
Optimum Tasarım, Kafes Yapılar, \\
Doğal Frekans Sınırlayıcıları, \\
JAYA Algoritması.
\end{tabular}

\section{ÖZET}

Bu çalışma ile düzlem ve uzay kafes yapıların doğal frekans sınırlayıcıları altında Jaya algoritması kullanılarak optimum (minimum ağırlıklı) tasarımı yapılmıștır. Jaya, Sanskritçe'de "Zafer" anlamına gelmektedir. Jaya algoritması (JA), optimum tasarım probleminin çözümünde en iyi çözüme yaklaşma ve en kötü çözümden uzaklaşma prensibini esas almaktadır. JA'nın geçerliliğini göstermek için daha önce farklı optimizasyon yöntemleri ile optimize edilmiş olan 200 elemanlı düzlem kafes ve 72 elemanlı uzay kafes yapılar kullanılmıştır. JA'nın performansı, optimum ağırlık ve optimum ağırlı̆̆ın elde edilmesi için gerekli yapı analiz sayısı bakımından literatürdeki diğer yöntemlerle kıyaslanmıştır. Bu kıyaslamalar, JA’nın literatürdeki diğer yöntemlerden daha iyi sonuçlar elde edebildiğini göstermektedir.

Doi: $10.24012 /$ dumf. 722958

\begin{tabular}{|c|c|}
\hline ARTICLE INFO & ABSTRACT \\
\hline Article history: & $\begin{array}{l}\text { In this study, Jaya algorithm (JA) is proposed for optimum design of planar and spatial trusses under natural } \\
\text { frequency constraints. Jaya means "Victory" in Sanskrit. The algorithm is based on the concept that the solution }\end{array}$ \\
\hline Received: 18 April 2020 & obtained for a given optimization problem which should move toward the best solution and must avoid the worst \\
\hline Revised: 8 May 2020 & solution. Sizing optimization of 200-bar planar and 72-bar spatial truss structures previously optimized by different \\
\hline Accepted: 15 May 2020 & optimization methods are used to demonstrate the validity of JA. The performance of JA is compared to other \\
\hline Keywords: & $\begin{array}{l}\text { optimization methods in terms of optimized weight and number of structural analyses required to obtain optimum } \\
\text { design. These comparisons showed that JA could obtain better results than other optimization methods in the }\end{array}$ \\
\hline $\begin{array}{l}\text { Optimum Design, Truss } \\
\text { Structures, Natural Frequency }\end{array}$ & literature. \\
\hline
\end{tabular}

Constraints, JAYA Algorith.

\footnotetext{
* Sorumlu yazar / Correspondence

$\bowtie \quad$ sozgurd@gmail.com
} 


\section{Giriș}

Klasik optimizasyon yöntemlerine alternatif olarak ortaya çıkan sezgisel optimizasyon yöntemleri her türlü optimizasyon probleminin çözümünde otuz yılı aşkın süredir kullanılmaktadır. Genetik algoritmalar (GA) [1], karınca koloni optimizasyonu (ACO) [2], parçacık sürü optimizasyonu (PSO) [3], öğretmeöğrenme esaslı optimizasyon (TLBO) [4] başlıca sezgisel optimizasyon yöntemleri arasındadır. Sezgisel optimizasyon yöntemlerinin ortak özelliği doğal bir olay veya süreçle optimizasyon problemleri arasında analoji kurmayı esas almalarıdır.

Kafes yapılar tüm dünyada en yaygın kullanılan yapı sistemleri arasındadır. Depo ve fabrika binaları, hangarlar, alışveriş merkezleri, kapalı spor salonları, kongre merkezleri vb. birçok inşaat projesinde kafes yap1 sistemleri tercih edilmektedir. $\mathrm{Bu}$ yaygın kullanımla birlikte nitelikli işçiliğin gerekliliği, periyodik bakım ve malzeme maliyeti dikkate alınarak kafes yapıların ekonomik olarak tasarlanması gerekmektedir. $\mathrm{Bu}$ amaçla, kafes yapıların optimum tasarımı konusunda farklı optimizasyon yöntemlerinin kullanıldığı çok sayıda çalışma yapılmıştır. $\mathrm{Bu}$ çalışmalarda, tasarım sinırlayıcıları olarak genelde gerilme ve deplasman sınırlayıcıları alınırken, bazılarında ise doğal frekans sınırlayıcıları kullanılmıştır.

Herhangi bir dış kuvvete maruz kalmasa bile her yapının belli bir frekansta titreşim hareketi yaptığı bilinmektedir. Doğal titreşim adı verilen bu titreşim, yapının kütlesi ve rijitliğine bağlı olarak hesaplanmaktadır. Herhangi bir yapıdaki doğal frekans sayısı yapının serbestlik derecesi sayısına eşit alınmaktadır.

Yapının zorlanmış titreşim (dışarıdan bir kuvvet uygulandığı durum) frekansları ile doğal titreşim frekanslarının çakışması halinde titreşim genliği çok büyük değerlere ulaşacaktır. Bunun sonucunda, rezonans ad1 verilen durum ortaya çıkarak yapıda toptan göçmeye neden olacaktır. Dolayısıyla doğal frekanslarının bilinmesi ve zorlanmış frekanslarla çakışmasının önlenmesi yap1 emniyeti açısından büyük önem arz etmektedir. Yapı sistemlerinin doğal frekansları özdeğer probleminin çözülmesi ile elde edilmektedir. $\mathrm{Bu}$ çözüm sonucu elde edilen en küçük özdeğer, sistemin birinci doğal frekansını ve elde edilen diğer özdeğerler sırasıyla sistemin sonraki doğal frekans değerlerini göstermektedir. Optimum tasarım probleminde ise, doğal frekans sınır değerlerini sağlayan minimum ağırlıklı yapının elde edilmesi amaçlanmaktadır.

Kafes yapıların doğal frekans sinırlayıcıları altında optimum tasarımı daha önce; modifiye edilmiş öğrenme-öğretme esaslı optimizasyon (MS-TLBO) [5], sinif-esaslı optimizasyon (SBO) [6], çevrimsel üreme algoritması (CPA) [7], titreşen parçacık sistem algoritması (VPS) [8], gelişmiş evrim algoritması ReDE [9], modifiye edilmiş ateş böceği algoritması (AHEFA) [10] , yapay kan dolaşımı algoritması (EACCS) [11] ve hipotrokoid sarmal optimizasyonu (HSPO) [12] gibi sezgisel optimizasyon yöntemleri kullanılarak icra edilmiștir.

Optimizasyon problemlerinin çözümünde kullanılan nispeten yeni olan bir diğer sezgisel optimizasyon yöntemi ise JAYA algoritmasıdır (JA). JA ilk olarak Rao [13] tarafindan sinırlayıcılı ve sinırlayıcısız fonksiyonların optimizasyonu için önerilmiş, sonrasında elektromekanik sistemlerinin optimum boyutlandırması [14] ve güç sistemlerinin optimizasyounu [15] gibi alanlarda kullanılmıştır. JA'nın yapı mühendisliğinde de uygulamaları mevcut [16,17] olmakla birlikte, yapılan çalışmalar kafes yapıların gerilme ve deplasman sinırlayıcıları altında optimum tasarımı konusundadır.

$\mathrm{Bu}$ çalışma ile JA'nın kafes yapıların doğal frekans sinırlayıcıları altında optimum tasarımında ilk kez kullanılması amaçlanmaktadır. JA'nın performansı daha önce farkl1 sezgisel optimizasyon yöntemleri kullanılarak optimum tasarımı yapılmış olan 200 elemanlı düzlem kafes ve 72 elemanlı uzay kafes yapıları üzerinde test edilmiştir. JA'nın performansı, optimum ağırlık ve optimum 
ağırlığın elde edilmesi için gerekli yapı analiz sayısı bakımından literatürdeki diğer yöntemlerle kıyaslanmıştır. $\mathrm{Bu}$ kıyaslamalar, JA'nın literatürdeki diğer yöntemlerden daha iyi sonuçlar elde edebildiğini göstermektedir. Çalışmada, ilk olarak optimum tasarım probleminin formülasyonu verilmiş, ardından JA açıklanmış ve JA ile kafes yapıların doğal frekans sinırlayıcıları altında optimum tasarım algoritması sunulmuştur. Daha sonra, JA ve diğer optimizasyon yöntemlerinden bulunan sonuçlar karşılaştırılmıştır. Son olarak ise çalışmadan elde edilen sonuçlar özetlenmiştir.

\section{Optimum \\ tasarımının formülasyonu}

probleminin

$\mathrm{Bu}$ çalışmada, doğal frekans sınırlayıcıları altında minimum ağırlıklı kafes yapıların elde edilmesi amaçlanmakta olup optimum tasarım problemi:

Amaç fonksiyonu:

Minimum $W(A)=\sum_{i=1}^{n g} A_{i} \sum_{j=1}^{m k} \rho_{j} L_{j}$

$A_{i}^{\text {min }} \leq A_{i} \leq A_{i}^{\text {maks }}, \quad i=1,2, \ldots, n g$

Tasarım değişkenleri: $A=\left[A_{1}, A_{2}, \ldots . ., A_{n g}\right]$

Doğal frekans sinırlayıcıları: $\omega_{k} \leq \omega_{k}^{u}$

$$
\omega_{l} \geq \omega_{l}^{l}
$$

şeklinde ifade edilebilir. Burada $A$ tasarım değişkenlerini (eleman gruplarını) içeren bir vektör olup her eleman grubuna ait enkesit alanlarını göstermektedir. $n g$ kafes yapıdaki tasarım değişkeni sayısını (eleman grup sayısı), $\rho_{j}$ ve $L_{j}$ sirasıyla $j$ 'nci elemanın özgül ağırlığını ve uzunluğunu, $m k$ ' $i$ nci tasarım değişkenindeki toplam eleman sayısını, $W(A)$ kafes yapının ağırlı̆̆ını, $A_{i}^{\text {min }}$ ve $A_{i}^{\text {maks }} i$ 'nci tasarım değişkeninin alabileceği minimum ve maksimum enkesit alanlarını, $\omega_{k}$ ve $\omega_{k}^{u}$ kafes yapının $k$ 'nci doğal frekans değerini ve bunun alabileceği en büyük değeri, $\omega_{l}$ ve $\omega_{l}^{l}$ kafes yapının l'nci doğal frekans değerini ve bunun alabileceği en küçük değeri göstermektedir.

Kafes yapıların optimum tasarımı yapılırken doğal frekans sınırlayıcılarını sağlayan veya sağlamayan tasarımları ayırt edebilmek için cezalandırılmış amaç fonksiyonu adı verilen bir fonksiyon kullanılmaktadır. Bu fonksiyon ile sınırlayıcıları sağlamayan kafes yapılar sınırlayıcı sağlamama derecelerine göre cezalandırılmaktadır. Cezalandırılmış amaç fonksiyonu $\left(f_{p}(A)\right)$ şu şekilde ifade edilebilir:

$f_{p}(A)=(1+v)^{\varepsilon} \times W(A)$

burada $\varepsilon$ üstel ceza katsayısı olup bu çalışmada 2 alınmıştır. $v$ sınır değerleri sağlamayan cezalı doğal frekans sınırlayıcılarının toplamı olup aşağıdaki gibi hesaplanır:

$v=\sum_{k=1}^{n k} v_{\omega}^{k}+\sum_{l=1}^{l k} v_{\omega}^{l}$

burada $n k$ ve $l k$ sirasiyla alttan ve üstten sınırlandırılmış doğal frekans sınırlayıcı sayısını, $v_{\omega}^{k}$ ve $v_{\omega}^{l}$ ise $k$ 'nci ve $l$ 'nci doğal frekanslar için ceza değerleri olup şu şekilde hesaplanır:

$v_{\omega}^{k}=0 \quad$ eğer $\quad \omega_{k} \leq \omega_{k}^{u}$

$v_{\omega}^{k}=\left|\frac{\omega_{k}-\omega_{k}^{u}}{\omega_{k}^{u}}\right|$ eğer $\quad \omega_{k}>\omega_{k}^{u}$

$v_{\omega}^{l}=0 \quad$ eğer $\quad \omega_{l} \geq \omega_{l}^{l}$

$v_{\omega}^{l}=\left\lceil\frac{\omega_{l}-\omega_{l}^{l}}{\omega_{l}^{l}}\right\rceil$ eğer $\quad \omega_{l}<\omega_{l}^{l}$

\section{JAYA algoritması (JA)}

JA optimizasyon sürecinde her iterasyonda tasarım değişkenlerini (kafes yapıdaki eleman grupları) modifiye ederek optimum çözümü elde etmeyi amaçlamaktadır. $A_{i, l, i t}$; it'nci iterasyondaki l-nci tasarım için $i$-ncl tasarım değişkenini temsil etmek üzere aşağıdaki bağıntıyla modifiye edilir:

$$
\begin{aligned}
& A_{i, l, i t}^{\text {yeni }}=A_{i, l, i t}+r_{1, i, i t}\left(A_{i, \text { best }, i t}-\left|A_{i, l, i t}\right|\right) \\
& -r_{2, i, i t}\left(A_{i, \text { worst }, i t}-\left|A_{i, l, i t}\right|\right)
\end{aligned}
$$


burada $A_{i, l, i t}^{\text {yeni }}$ modifiye edilmiş tasarım değişkenini, $r_{1, i, i t}$ ve $r_{2, i, i t}$ it'nci iterayondaki i'ncl tasarım değişkeni için $[0,1]$ aralığında rastgele üretilen reel say1lar1, $A_{i, \text { best, }, \text { ti }}$ ve $A_{i, \text { worst }, \text { it }}$ it'nci iterasyondaki en iyi ve en kötü tasarımların $i$ 'nci tasarım değişkenini göstermektedir. Denklemdeki $\quad r_{1, i, i t}\left(A_{i, \text { best }, i t}-\left|A_{i, l, i t}\right|\right) \quad$ mevcut vii. tasarımın en iyi tasarıma yaklaşma eğilimini, $-r_{2, i, i t}\left(A_{i, \text { worst }, i t}-\left|A_{i, l, i t}\right|\right)$ mevcut tasarımın en kötü tasarımdan uzaklaşma eğilimini ifade etmektedir. $r_{1, i, i t}$ ve $r_{2, i, i t}$ reel sayıları tasarım uzayının daha etkili araştırılmasını sağlarken, $\left|A_{k, l, i t}\right|$ mutlak değeri arama kabiliyetinin güçlendirilmesini sağlamaktadır [13].

JA'da ilk olarak popülasyon sayısı kadar rasgele olarak başlangıç tasarımları üretilir. Sonrasında popülasyondaki her bir tasarım (7) bağıntısıyla modifiye edilerek yeni bir tasarım elde edilir. Yeni tasarım önceki tasarımdan daha iyi ise önceki tasarımın yerine geçer, aksi halde önceki tasarım değişmez. Popülasyondaki tüm tasarımlar için bu işlemler tekrarlanarak bir iterasyon tamamlanır. Her iterasyonda ayn işlemler tekrarlanır. Maksimum iterasyon sayısının aşılması durumunda optimizasyon işlemi bitirilir.

JA ile kafes yapıların doğal frekans sınırlayıcıları altında optimum tasarım algoritması aşağıdaki adımlardan oluşmaktadır:

$i$. Popülasyon sayısını $(n p)$ ve maksimum iterasyon sayısını (itmaks) belirle. Burada popülasyondaki her bir tasarım bir kafes yapıyı temsil etmektedir. Her kafes yapı tasarımı için yapı analizi yaparak, (1)-(6) bağıntıları ile cezalandırılmış amaç fonksiyonunu elde et. İterasyon sayacinı başlat, $i t=0$.

ii. İterasyon sayacını arttır, $i t=i t+1$.

iii. $\quad$ En iyi $\left(f_{p}^{\min }(A)\right)$ ve en kötü $\left(f_{p}^{\text {maks }}(A)\right)$ cezalandırılmış amaç fonksiyonuna sahip kafes yap1 tasarımlarını belirle. Kafes yap1 tasarım sayacını sifirla $i d=0$.

$i v$. Kafes yap 1 tasarım sayacın 1 arttır $i d=i d+1$. v. (7) bağıntısı ile kafes yapıdaki tüm tasarım değişkenlerini modifiye ederek yeni kafes yapı tasarımını elde et.

vi. Yeni kafes yap1 tasarımı için yap1 analizi yap, (1)-(6) bağıntıları vasıtasıyla cezalandırılmış amaç fonksiyonunu elde et $\left(f_{p}^{\text {yeni }}(A)\right)$.

Yeni elde edilen kafes yapıya ait cezalandırılmış amaç fonksiyonunu ile önceki kafes yapıya ait cezalandırılmış amaç fonksiyonunu kıyasla. Ĕger $f_{p}^{y e n i}(A) \leq$ $f_{p}^{i d}(A)$ ise, yeni üretilen tasarımı önceki tasarımın yerine ata, aksi halde önceki tasarımı değiştirme.

viii. Ĕger $i d=p s$ ise, ix'nci adıma git, değilse $i v$ 'ncü adıma git.

ix. $\quad$ Eğer $i t=i t_{m a k s . ~}$ ise $x$ 'ncu adıma git, değilse ii'nci adıma git.

$x$. Doğal frekans sınırlayıcılarını sağlayan minimum ağırlıklı kafes yapı tasarımını optimum tasarım olarak ata, optimizasyon işlemini bitir.

\section{Tasarım örnekleri}

Daha önce MS-TLBO [5], SBO [6], CPA [7], VPS [8], ReDE [9], AHEFA [10], EACCS [11] ve HSPO [12] yöntemleri kullanılarak optimum tasarımı yapılmış olan 200 elemanlı düzlem kafes ve 72 elemanlı uzay kafes yapılar bu çalışmada JA yöntemi ile optimize edilmiş ve elde edilen sonuçlar kıyaslanmıştır.

Çalışmada sunulan algoritma MATLAB programlama dilinde kodlanmıştır. Yapılan kodlamanın icrası ile elde edilen sonuçların doğruluğu, SAP 2000 v20 [18] yap1 analiz programıla teyit edilmiştir.

JA, farklı popülasyon sayısı $(n p)$ değerleri için ayrı ayrı icra edilmiş ve en hafif kafes yapı ağırlığ $n p=20$ için elde edildiğinden popülasyon büyüklügü 20 olarak seçilmiştir. JA'nın farklı başlangıç tasarımları için birbirine yakın sonuçlar elde edip edemeyeceği test edilmek istenmiştir. $\mathrm{Bu}$ amaçla, yöntem 20 farklı başlangıç popülasyonu için 20 farklı kez icra 
edilmiştir. Bu farklı icralar sonunda bulunan yapı tasarımları arasında optimum (minimum ağırlıklı) olan kafes yapının ağırlığı, bu kafes yapıya ait tasarım değişkenleri, optimum ağırlığın bulunması için gerekli yapı analiz sayısı ve doğal frekans sınırlayıcıları için ihlal yüzdeleri tablolarda verilmiştir. Ayrıca, 20 farklı tasarım için elde edilen ortalama ağırlık ve standart sapma gibi istatiksel verilerde tablolarda sunulmuştur. 200 elemanlı düzlem kafes ve 72 elemanlı uzay kafes yapılara ait malzeme özellikleri, enkesit alanlarının alabileceği sınır değerleri ve doğal frekans sınırlayıcıları için tanımlanan sınır değerler Tablo 1'de verilmiştir.

Tablo 1. Tasarım örneklerine ait malzeme özellikleri, enkesit alan sınırları ve doğal frekans sinırlayıcıları.

\begin{tabular}{|c|c|c|c|c|}
\hline Tasarım örneği & $\begin{array}{l}\text { Elastisite } \\
\text { modülü } \\
E\left(\mathrm{~N} / \mathrm{m}^{2}\right)\end{array}$ & $\begin{array}{l}\text { Malzeme } \\
\text { özgül ağırlığ1 } \\
\rho\left(\mathrm{kg} / \mathrm{m}^{3}\right)\end{array}$ & $\begin{array}{l}\text { Enkesit } \\
\text { alan sınırları }\left(\mathrm{m}^{2}\right)\end{array}$ & $\begin{array}{l}\text { Doğal frekans } \\
\text { sinırlayıcıları }(\mathrm{Hz})\end{array}$ \\
\hline 200 elemanlı düzlem kafes & $2.1 \times 10^{11}$ & 7860 & \multirow{2}{*}{$\begin{array}{l}0.1 \times 10^{-4} \leq A \\
645 \times 10^{-4} \leq A \leq 20 \times 10^{-4}\end{array}$} & $\omega_{1} \geq 5, \omega_{2} \geq 10, \omega_{3} \geq 15$ \\
\hline 72 elemanlı uzay kafes & $6.89 \times 10^{10}$ & 2770 & & $\omega_{1}=4, \omega_{2}=4, \omega_{3} \geq 6$ \\
\hline
\end{tabular}

\section{0 elemanlı düzlem kafes yapt}

200 elemanlı düzlem kafes yapı Şekil 1'deki gösterilmiştir. Kafes yapıda 29 tasarım değişkeni mevcuttur. Tasarım değişkenleri ve bunların ihtiva ettiği elemanlar Tablo 2'de verilmiştir. Yapının en üst katındaki düğüm noktalarında $100 \mathrm{~kg}$ ilave kütle mevcuttur.
Tablo 3'de JA ve literatürdeki diğer yöntemlerden elde edilen optimum tasarım sonuçları karşılaştırılmıştır. Tablo 4'de ise; Tablo 3'deki optimum tasarımlara ait ilk üç doğal frekans değerleri ve aynı tasarımların SAP 2000 v20'de [18] analizi sonucu bulunan değerler karşılaştırmalı olarak sunulmuştur.

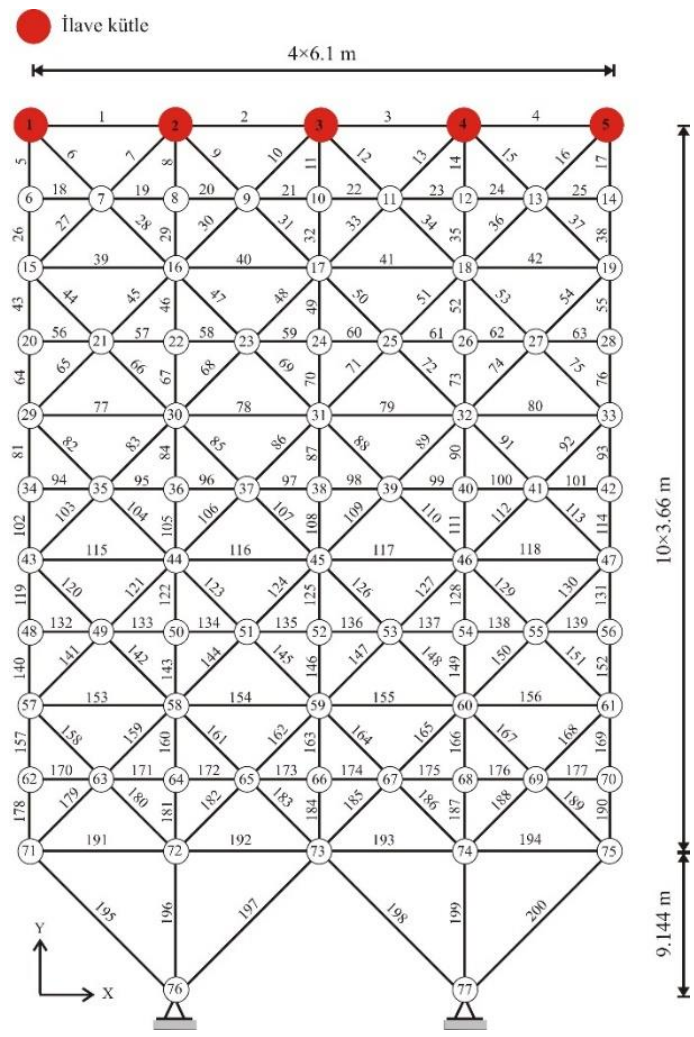

Şekil 1. 200 elemanlı düzlem kafes yapı 
Tablo 2. 200 elemanlı düzlem kafes yapıya ait tasarım değişkenleri

\begin{tabular}{llll}
\hline $\begin{array}{l}\text { Tasarım } \\
\text { değişkeni }\end{array}$ & Eleman numarası & $\begin{array}{l}\text { Tasarım } \\
\text { değişkeni }\end{array}$ & Eleman numaras 1 \\
\hline 1 & $1,2,3,4$ & 16 & $82,83,85,86,88,89,91,92,103,104,106$, \\
& & & $107,109,110,112,113$ \\
2 & $5,8,11,14,17$ & 17 & $115,116,117,118$ \\
3 & $19,20,21,22,23,24$ & 18 & $119,122,125,128,131$ \\
4 & $18,25,56,63,94,101,132,139,170,177$ & 19 & $133,134,135,136,137,138$ \\
5 & $26,29,32,35,38$ & 20 & $140,143,146,149,152$ \\
6 & $6,7,9,10,12,13,15,16,27,28,30,31,33$, & 21 & $120,121,123,124,126,127,129$, \\
& $34,36,37$ & & $130,141,142,144,145,147,148,150,151$ \\
7 & $39,40,41,42$ & 22 & $153,154,155,156$ \\
8 & $43,46,49,52,55$ & 23 & $157,160,163,166,169$ \\
9 & $57,58,59,60,61,62$ & 24 & $171,172,173174,175,176$ \\
10 & $64,67,70,73,76$ & 25 & $178,181,184,187,190$ \\
11 & $44,45,47,48,50,51,53,54,65,66,68,69$, & 26 & $158,159,161,162,164,165,167,168,179$, \\
& $71,72,74,75$ & & $180,182,183,185,186,188,189$ \\
12 & $77,78,79,80$ & 27 & $191,192,193,194$ \\
13 & $81,84,87,90,93$ & 28 & $195,197,198,200$ \\
14 & $95,96,97,98,99,100$ & 29 & 196,199 \\
15 & $102,105,108,111,114$ & & \\
\hline
\end{tabular}

Tablo 3. 200 elemanlı düzlem kafes yapıda optimum tasarım sonuçlarının karşılaştırılması

\begin{tabular}{lllllll}
\hline $\begin{array}{l}\text { Tasarım } \\
\text { değişkenleri } \\
\mathrm{A}_{\mathrm{i}}\left(\mathrm{cm}^{2}\right)\end{array}$ & $\begin{array}{l}\text { MS-TLBO } \\
{[5]}\end{array}$ & $\begin{array}{l}\text { SBO } \\
{[6]}\end{array}$ & $\begin{array}{l}\text { AHEFA } \\
{[10]}\end{array}$ & $\begin{array}{l}\text { EACCS } \\
{[11]}\end{array}$ & $\begin{array}{l}\text { HSPO } \\
{[12]}\end{array}$ & JA \\
\hline 1 & & & & & & \\
2 & 0.29167 & 0.3040 & 0.29930 & 0.31750 & 0.30143 & 0.29714 \\
3 & 0.48527 & 0.4478 & 0.45080 & 0.44520 & 0.45938 & 0.489687 \\
4 & 0.10005 & 0.1000 & 0.10010 & 0.10040 & 0.07811 & 0.100000 \\
5 & 0.1000 & 0.1000 & 0.1000 & 0.10040 & 0.0983 & 0.100729 \\
6 & 0.49666 & 0.5075 & 0.51230 & 0.49640 & 0.50624 & 0.557893 \\
7 & 0.8318 & 0.8219 & 0.8205 & 0.8226 & 0.8199 & 0.793506 \\
8 & 0.10000 & 0.1003 & 0.10110 & 0.10950 & 0.10000 & 0.100000 \\
9 & 1.40851 & 1.4240 & 1.41560 & 1.38780 & 1.39676 & 1.435431 \\
10 & 0.10000 & 0.1001 & 0.10000 & 0.10060 & 0.10000 & 0.101238 \\
11 & 1.58732 & 1.5929 & 1.57420 & 1.54650 & 1.57350 & 1.649521 \\
12 & 1.1249 & 1.1597 & 1.1597 & 1.1514 & 1.1490 & 1.148061 \\
13 & 0.10078 & 0.1275 & 0.13380 & 0.15920 & 0.11859 & 0.108915 \\
14 & 2.98830 & 2.9765 & 2.96720 & 2.99790 & 3.10264 & 2.972128 \\
15 & 0.10234 & 0.1001 & 0.10000 & 0.10070 & 0.10000 & 0.100000 \\
16 & 3.33456 & 3.2456 & 3.27220 & 3.27260 & 3.24327 & 3.421181 \\
17 & 1.5990 & 1.5818 & 1.5762 & 1.5753 & 1.5968 & 1.569461 \\
18 & 0.18763 & 0.2566 & 0.25620 & 0.27680 & 0.24217 & 0.143344 \\
19 & 5.14985 & 5.1118 & 5.09560 & 5.04340 & 5.39675 & 5.286264 \\
20 & 0.10059 & 0.1001 & 0.10010 & 0.10760 & 0.10000 & 0.100000 \\
& 5.37321 & 5.4337 & 5.45460 & 5.44900 & 5.25824 & 5.577982
\end{tabular}




\begin{tabular}{lllllll}
21 & 2.0885 & 2.1016 & 2.0933 & 2.1447 & 2.1434 & 2.091733 \\
22 & 0.63412 & 0.6794 & 0.67370 & 0.67450 & 0.8293 & 0.657104 \\
23 & 7.66597 & 7.6581 & 7.64980 & 7.69670 & 7.30130 & 7.778857 \\
24 & 0.10000 & 0.1006 & 0.11780 & 0.13530 & 0.11284 & 0.100000 \\
25 & 7.99043 & 7.9468 & 8.06820 & 7.71060 & 7.91076 & 7.984943 \\
26 & 2.8246 & 2.7835 & 2.8025 & 2.7915 & 2.86741 & 2.836508 \\
27 & 10.42712 & 10.5277 & 10.50400 & 10.37550 & 10.8526 & 10.52663 \\
28 & 21.42957 & 21.3027 & 21.29350 & 21.33640 & 20.89930 & 21.66231 \\
29 & 10.63218 & 10.6207 & 10.74100 & 10.73450 & 10.75149 & 10.29429 \\
\hline Optimum ağırlık (kg) & 2160.351 & 2156.5070 & 2160.7445 & 2156.3651 & 2157.7116 & 2172.22571 \\
Ortalama ağıllık (kg) & 2214.627 & 2156.7870 & 2161.0393 & 2157.6554 & 2169.0492 & 2193.155 \\
Standart sapma (kg) & 87.1835 & 0.2110 & 0.1783 & 1.7683 & 10.8148 & 10.70989 \\
Sınırlayıcı ihlal & 0.7553 & 1.0070 & 0.9947 & 0.9867 & 0.236 & 0.0000 \\
yüzdesi (\%) & & & & & & \\
Yapı analiz sayıs1 & 10000 & 23000 & 11300 & 23000 & 11640 & 13240 \\
\hline
\end{tabular}

Tablo 4. 200 elemanlı düzlem kafes yapıda optimum tasarımlara ait doğal frekans değerleri

\begin{tabular}{lllllll}
\hline $\begin{array}{l}\text { Frekans no } \\
(\mathrm{Hz})\end{array}$ & $\begin{array}{l}\text { MS-TLBO } \\
{[5]}\end{array}$ & $\begin{array}{l}\text { SBO } \\
{[6]}\end{array}$ & $\begin{array}{l}\text { AHEFA } \\
{[10]}\end{array}$ & $\begin{array}{l}\text { EACCS } \\
{[11]}\end{array}$ & $\begin{array}{l}\text { HSPO } \\
{[12]}\end{array}$ & JA \\
\hline 1 & & & & & & \\
\hline $1^{*}$ & 5.0000 & 5.0000 & 5.0000 & 5.0000 & 5.0000 & 5.000011 \\
2 & 4.9896 & 4.9878 & 4.9904 & 4.9871 & 4.9882 & 5.000011 \\
$2^{*}$ & 12.1366 & 12.21412 & 12.1821 & 12.3137 & 12.1499 & 12.26016 \\
3 & 12.1117 & 12.1850 & 12.1516 & 12.2835 & 12.1213 & 12.26016 \\
$3^{*}$ & 15.0529 & 15.01918 & 15.0160 & 15.0226 & 15.0004 & 15.01977 \\
\hline
\end{tabular}

*SAP 2000 v20'den [18] elde edilen doğal frekans değerleri

JA ile $2172.2257 \mathrm{~kg}$ ağırlığındaki optimum tasarım 13240 yap1 analizi sonunda elde edilmiştir. Tablo 3 incelendiğinde ilk başta JA ile bulunan optimum tasarımın, tüm yöntemlerden daha ağır olduğu gözükmektedir. Ancak, JA dişındaki tüm yöntemlerin Tablo 1'de verilen $\omega_{1}$ ve $\omega_{3}$ doğal frekans sınırlayıcılarını \%0.236 ile $\% 1.007$ arasında değişen oranlarda ihlal ettiği, JA'nın ise doğal frekans sınırlayıcılarını tam olarak sağladığı tespit edilmiştir. Başka bir deyişle, Tablo 3'de sunulan tasarımlar arasında yapilabilir (feasible) olan tek tasarım JA ile elde edilmiştir. Diğer yöntemlerden elde edilen tasarımlar doğal frekans sınırlayıcılarını ihlal ettiğinden optimum tasarım olarak kabul edilmeleri mümkün değildir. Tablo 4'de doğal frekans değerleri karşılaştırıldığında JA ve SAP 2000 v20'den [18] elde edilen doğal frekans değerlerinin aynı olduğu görülmektedir. $\mathrm{Bu}$ durum, JA için geliştirilen MATLAB kodunun doğruluğunu kanıtlamaktadır.

Tablo 3'de, JA'nın 20 farklı icrası sonunda bulunan 20 farklı nihai tasarım için hesaplanan standart sapma değeri 10.70989 $\mathrm{kg}$ olarak verilmiştir. Bu değer, 2193.155 $\mathrm{kg}$ olan ortalama değerin sadece \%0.49'u mertebesindedir. $\mathrm{Bu}$ sonuç, JA'nın farklı başlangıç popülasyonları üretmesine karşın 
birbirine oldukça yakın tasarımları bulabildiğini kanıtlamaktadır.

Tablo 3'de verilen diğer yöntemler doğal frekans sınırlayıcılarını ihlal ettiğinden optimum tasarımı bulmak için gereken yapı analiz sayıs1 bakımından JA ile karşılaştırmaları objektif bir değerlendirme

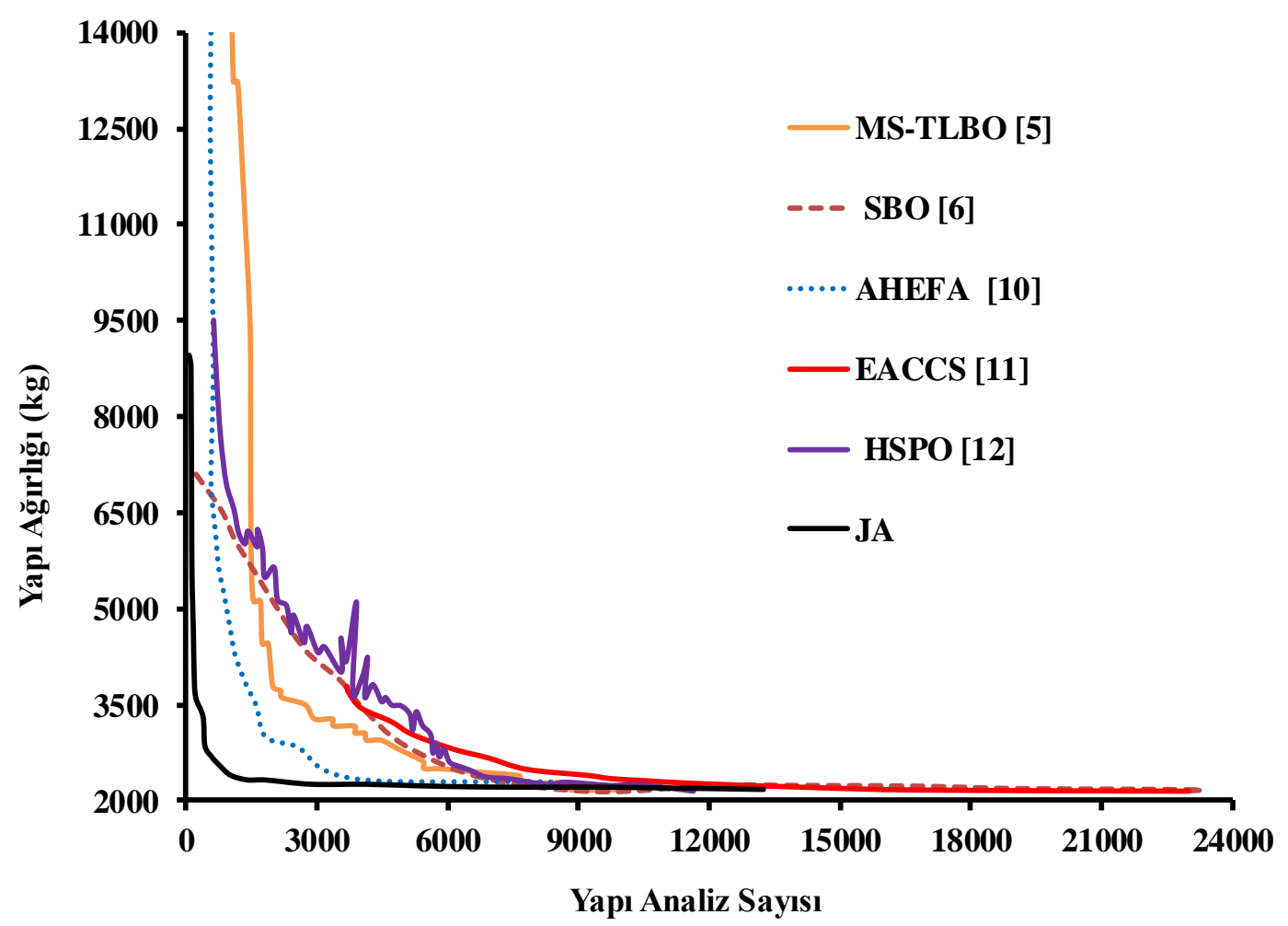

Şekil 2. 200 elemanlı düzlem kafeste yapı ă̆ırlı̆̆ ile yapı analiz sayısının değişimi

Şekil 2'deki eğriler incelendiğinde, JA'nın diğer tüm yöntemlerden daha önce optimum tasarıma yakın sonuçları bulabildiği görülmektedir. JA, $2253.338 \mathrm{~kg}$ ağırlığında optimum ağırlığa oldukça yakın bir tasarımı sadece 2258 yapı analizi sonunda elde etmiştir. Bu durum; JA'nın optimum tasarıma yakın tasarımları oldukça hızlı bir şekilde bulabildiğini göstermektedir. olmayacaktır. Bununla birlikte, JA'nın SBO [6] ve EACSS [11] yöntemlerinden daha az analiz sayısı gerektirdiği de görülmektedir. 200 elemanlı düzlem kafeste JA ve diğer yöntemlerin optimizasyon sürecinde elde ettikleri yapı ağırlıklarının yapı analiz sayıları ile değişimi Şekil 2'deki gibidir. 


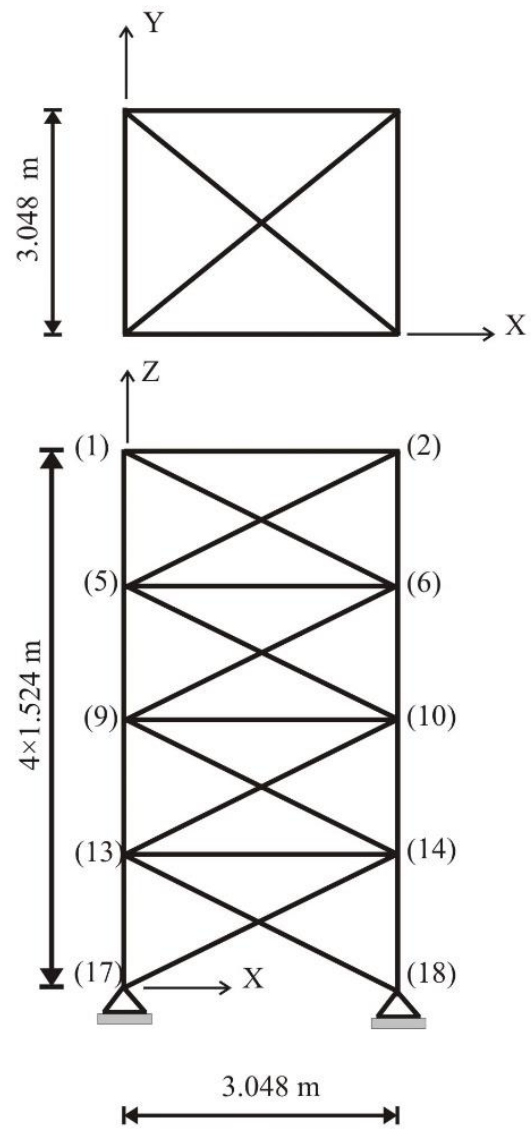

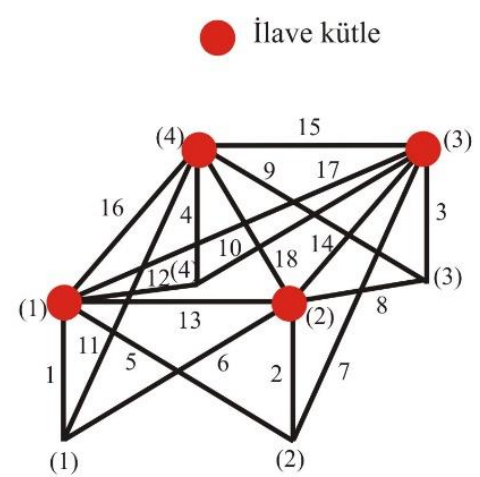

(b)

(a)

Şekil 3.72 elemanlı uzay kafes yapı (a) boyutlar (b) en üst kat eleman ve düğ̈̈m numaralandırılması

Tablo 5. 72 elemanlı uzay kafes yapıda optimum tasarım sonuçlarının karşılaştırılması

\begin{tabular}{|c|c|c|c|c|c|c|c|c|c|}
\hline $\begin{array}{l}\text { Tasarım } \\
\text { değişkenleri } \\
\mathrm{A}_{\mathrm{i}}\left(\mathrm{cm}^{2}\right)\end{array}$ & $\begin{array}{l}\text { MS- } \\
\text { TLBO } \\
{[5]}\end{array}$ & $\begin{array}{c}\text { SBO } \\
{[6]}\end{array}$ & $\begin{array}{l}\text { VPS } \\
{[7]}\end{array}$ & $\begin{array}{c}\text { CPA } \\
{[8]}\end{array}$ & $\begin{array}{c}\text { ReDE } \\
\text { [9] }\end{array}$ & $\begin{array}{c}\text { AHEFA } \\
{[10]}\end{array}$ & $\begin{array}{c}\text { EACCS } \\
{[11]}\end{array}$ & $\begin{array}{c}\text { HSPO } \\
{[12]}\end{array}$ & JA \\
\hline $\mathrm{A}_{1}-\mathrm{A}_{4}$ & 3.33350 & 3.49170 & 3.50170 & 3.32900 & 3.53270 & 3.56120 & 3.71220 & 3.43147 & 3.410165 \\
\hline$A_{5}-A_{12}$ & 7.90540 & 7.94140 & 7.93400 & 7.84100 & 7.83030 & 7.87360 & 7.74340 & 7.84360 & 7.640199 \\
\hline $\mathrm{A}_{13}-\mathrm{A}_{16}$ & 0.64690 & 0.64500 & 0.64500 & 0.64500 & 0.64530 & 0.64500 & 0.64680 & 0.64500 & 0.64500 \\
\hline $\mathrm{A}_{17}-\mathrm{A}_{18}$ & 0.64510 & 0.64500 & 0.64500 & 0.64500 & 0.64590 & 0.64510 & 0.69700 & 0.64500 & 0.64500 \\
\hline $\mathrm{A}_{19}-\mathrm{A}_{22}$ & 7.99800 & 8.11540 & 8.02150 & 8.41600 & 8.00290 & 7.97100 & 8.28840 & 8.03902 & 7.88633 \\
\hline$A_{23}-A_{30}$ & 7.76820 & 8.05330 & 7.98260 & 8.16000 & 7.91350 & 7.89280 & 8.21410 & 7.93058 & 8.05561 \\
\hline $\mathrm{A}_{31}-\mathrm{A}_{34}$ & 0.64500 & 0.64500 & 0.64500 & 0.64500 & 0.64510 & 0.64500 & 0.66580 & 0.64502 & 0.64500 \\
\hline $\mathrm{A}_{35}-\mathrm{A}_{36}$ & 0.64500 & 0.64500 & 0.64500 & 0.64500 & 0.645 & 0.64510 & 0.67430 & 0.64500 & 0.64500 \\
\hline $\mathrm{A}_{37}-\mathrm{A}_{40}$ & 12.8748 & 12.8569 & 12.8175 & 13.0780 & 12.7626 & 12.5404 & 12.1500 & 12.70402 & 12.96987 \\
\hline $\mathrm{A}_{41}-\mathrm{A}_{48}$ & 8.08550 & 8.04250 & 8.11290 & 8.04300 & 7.96570 & 7.96390 & 7.87000 & 7.96843 & 7.991384 \\
\hline $\mathrm{A}_{49}-\mathrm{A}_{52}$ & 0.64500 & 0.64510 & 0.64500 & 0.64500 & 0.64520 & 0.64590 & 0.70580 & 0.64505 & 0.64500 \\
\hline $\mathrm{A}_{53}-\mathrm{A}_{54}$ & 0.64500 & 0.64500 & 0.64500 & 0.64500 & 0.64500 & 0.64620 & 0.65260 & 0.64500 & 0.64500 \\
\hline $\mathrm{A}_{55}-\mathrm{A}_{58}$ & 17.0410 & 17.2136 & 17.3362 & 16.9430 & 16.9041 & 17.1323 & 17.0882 & 17.01693 & 16.83402 \\
\hline$A_{59}-A_{66}$ & 8.00030 & 8.08040 & 8.10100 & 8.14300 & 8.04340 & 8.02160 & 7.94720 & 8.01267 & 8.185437 \\
\hline $\mathrm{A}_{67}-\mathrm{A}_{70}$ & 0.64500 & 0.64500 & 0.64500 & 0.64700 & 0.64510 & 0.64500 & 0.64500 & 0.64500 & 0.64500 \\
\hline $\mathrm{A}_{71}-\mathrm{A}_{72}$ & 0.64950 & 0.64500 & 0.64500 & 0.65300 & 0.64730 & 0.64510 & 0.74620 & 0.64500 & 0.64500 \\
\hline
\end{tabular}




\begin{tabular}{|c|c|c|c|c|c|c|c|c|c|}
\hline $\begin{array}{l}\text { Optimum } \\
\text { ağırlık (kg) }\end{array}$ & 324.3754 & 327.5528 & 327.649 & 328.490 & 324.2467 & 324.2376 & 325.1956 & 324.2337 & $\begin{array}{l}324.9658 \\
{[327.649]^{1}} \\
{[328.490]^{2}}\end{array}$ \\
\hline $\begin{array}{l}\text { Ortalama } \\
\text { ağırlık (kg) }\end{array}$ & 325.74940 & 327.67970 & 327.67000 & 330.91 & 324.3219 & 324.41090 & $\mathrm{NA}^{*}$ & 325.41860 & 325.1190 \\
\hline $\begin{array}{l}\text { Standart } \\
\text { sapma }(\mathrm{kg})\end{array}$ & 0.91860 & 0.06750 & 0.01800 & 1.8400 & 0.05160 & 0.24200 & $\mathrm{NA}^{*}$ & 0.89850 & 0.1056 \\
\hline $\begin{array}{l}\text { Sinırlayıcı } \\
\text { ihlal } \\
\text { yüzdesi (\%) }\end{array}$ & 0.16500 & 0.58000 & 0.58750 & 0.66250 & 0.16830 & 0.17000 & 0.15830 & 0.16330 & 0.00000 \\
\hline $\begin{array}{l}\text { Yap1 analiz } \\
\text { sayıs1 }\end{array}$ & 4000 & 15000 & 6860 & 12800 & 11116 & 8860 & 12000 & 8820 & 13280 \\
\hline
\end{tabular}

${ }^{1}$ JA ile VPS'ye [7] ait ağırlık (327.649 kg) 3399 yapı analizde bulunmuştur.

${ }^{2} J A$ ile CPA'ya [8] ait ağırlık (328.490 kg) 2961 yapı analizde bulunmuştur.

*NA: Mevcut değil.

Tablo 6. 72 elemanlı uzay kafes yapıda optimum tasarımlara ait doğal frekans dĕgerleri

\begin{tabular}{lccccccccc}
\hline $\begin{array}{l}\text { Frekans } \\
\text { No }(\mathrm{Hz})\end{array}$ & $\begin{array}{c}\text { MS- } \\
\text { TLBO } \\
{[5]}\end{array}$ & $\begin{array}{c}\text { SBO } \\
{[6]}\end{array}$ & $\begin{array}{c}\text { VPS } \\
{[7]}\end{array}$ & $\begin{array}{c}\text { CPA } \\
{[8]}\end{array}$ & $\begin{array}{c}\text { ReDE } \\
{[9]}\end{array}$ & $\begin{array}{c}\text { AHEFA } \\
{[10]}\end{array}$ & $\begin{array}{c}\text { EACCS } \\
{[11]}\end{array}$ & $\begin{array}{c}\text { HSPO } \\
{[12]}\end{array}$ & JA \\
\hline 1 & & & & & & & & & \\
$1^{*}$ & 4.0011 & 4.0000 & 4.0000 & 4.0000 & 4.0000 & 4.0000 & 4.0000 & 4.0000 & 4.0000 \\
2 & 4.0015 & 4.0232 & 4.0235 & 4.0265 & 4.0004 & 4.0004 & 4.0005 & 4.0002 & 4.0000 \\
$2^{*}$ & 4.0011 & 4.0000 & 4.0002 & 4.0000 & 4.0000 & 4.0000 & 4.0000 & NA & 4.0000 \\
3 & 4.0015 & 4.0232 & 4.0235 & 4.0265 & 4.0004 & 4.0004 & 4.0005 & 4.0002 & 4.0000 \\
$3^{*}$ & 6.0003 & 6.000 & 6.0000 & 6.0000 & 6.0001 & 6.0000 & 6.0007 & 6.0000 & 6.0001 \\
\hline
\end{tabular}

*SAP 2000 v20'den [18] elde edilen doğal frekans değerleri

Tablo 5'de görüldüğü üzere, diğer yöntemler doğal frekans sinırlayıcılarını $\% 0.1633-\% 0.6625$ arasında değişen oranlarda ihlal etmelerine karşın JA ile bulunan optimum tasarım, sinırlayıcıları tam olarak sağlamaktadır. Dolayısıyla, JA ile diğer tüm yöntemlerden daha iyi bir tasarım elde edilmiştir.

Ayrica Tablo 6'da sunulduğu üzere, JA ile elde edilen doğal frekans değerlerinin SAP 2000 v20 [18] ile bulunan doğal frekans değerleriyle eşit olması MATLAB programlama dilinde yapılan kodlamanın doğruluğunu ispatlamaktadır.
Tablo 5'deki JA için verilen $0.1056 \mathrm{~kg}$ ' $1 \mathrm{k}$ standart sapma değerinin ortalama ağırlığın $\% 0.033$ mertebesinde olmas1 JA'nın farklı başlangıç popülasyonları için birbirine oldukça yakın sonuçları elde edebildiğini kanitlamaktadir.

72 elemanlı uzay kafeste yapı ağırlığ 1 ile yap1 analiz sayısının optimizasyon işlemi süresince değişimi Şekil 4'deki gibidir. JA, sadece 2661 yapı analizi sonunda 331.2597 $\mathrm{kg}$ gibi optimum tasarıma oldukça yakın bir tasarım bulmuştur. Bu sonuç, JA'nın çok hızlı bir şekilde optimum tasarıma yakın tasarımlar bulabildiğini göstermektedir. 


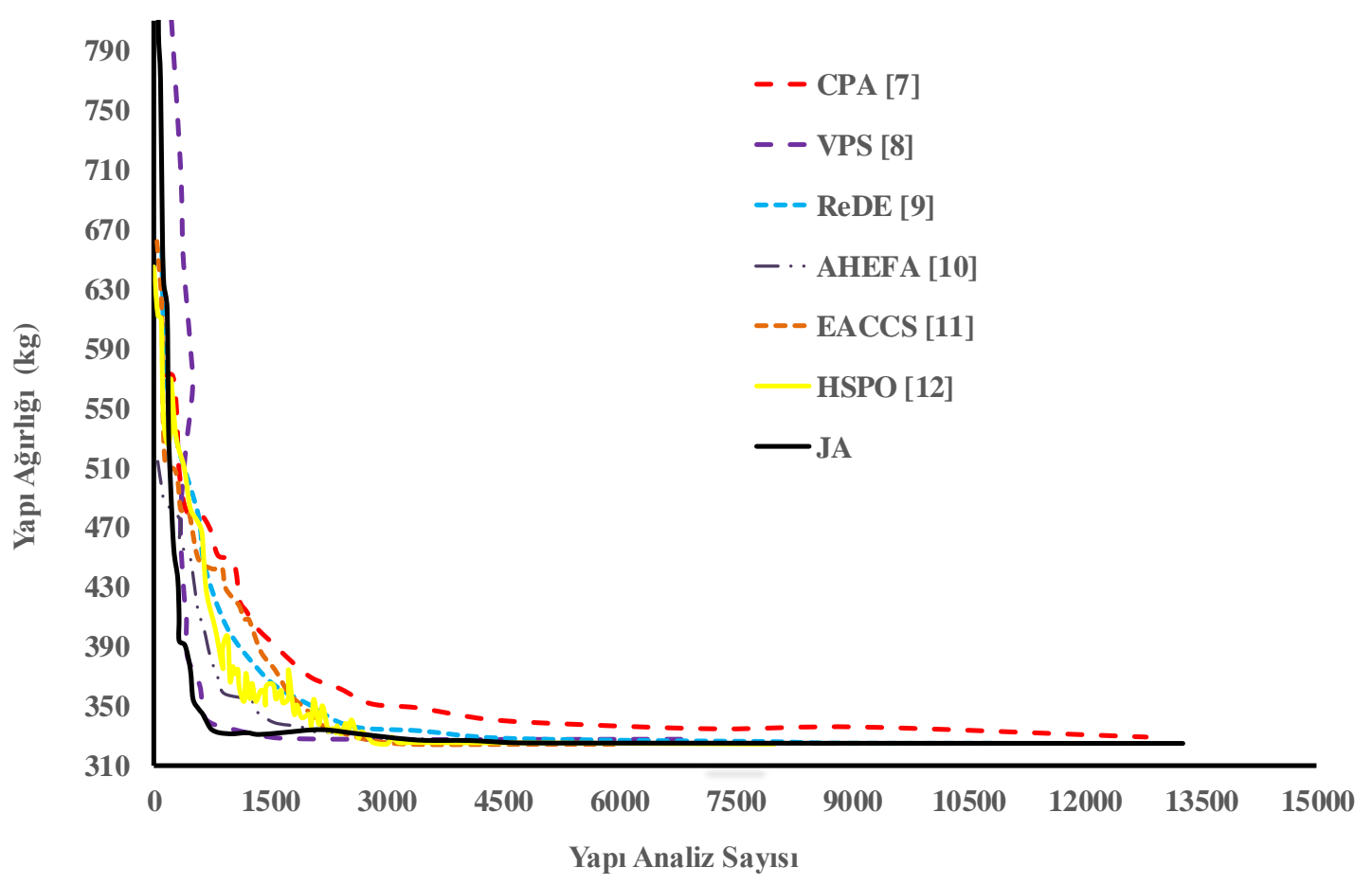

Şekil 4.72 elemanlı uzay kafeste yapı ă̆ırlı̆̆ı ile yapı analiz sayısının değişimi

\section{Sonuçlar}

Literatürdeki sonuçlarla yapılan kıyaslamalar JA'nın diğer tüm yöntemlerden daha iyi (yapılabilir) kafes yapılar elde ettiğini göstermektedir. Literatürdeki diğer yöntemlerden elde edilen optimum tasarımlar doğal frekans sınırlayıcılarını \%0.1633$\% 1.007$ arasında değişen oranlarda ihlal ederken, JA ile bulunan optimum tasarımlar sinırlayıcıları tam olarak sağlamaktadır. Ayrıca JA optimum tasarıma yakın tasarımlara çok hızlı bir şekilde ulaşabilmektedir. Yöntemin farklı icraları sonucunda bulunan tasarımlar için hesaplanan standart sapma değerlerinin ortalama ağırlığa göre oldukça küçük olması JA'nın farklı başlangıç popülasyonları üretmesine rağmen, optimizasyon işleminin sonunda birbirine çok yakın tasarımlar elde edebilme kabiliyetinin olduğunu ispatlamaktadır.

\section{Teşekkür}

$\mathrm{Bu}$ araştırma Dicle Üniversitesi Bilimsel Araştırma Projeleri Koordinasyon Birimi Koordinatörlüğü'nce desteklenmiştir. Proje Numarası: Mühendislik.18.002, 2018.

\section{Kaynaklar}

[1] J.H. Holland, Adaptation in Natural and Artificial Systems. Ann Arbor The University of Michigan Press, 1975.

[2] M. Dorigo, V. Maniezzo and A. Colorni, "The ant system: optimization by a colony of cooperating agents", IEEE Trans. Syst. Man. Cybern. B, 29-41, (1996).

[3] R.C. Eberhart, J. Kennedy, A new optimizer using particle swarm theory: Proceedings of The Sixth International Symposium on Micro Machine and Human Science, Nagoya, Japan, 19421948, (1995).

[4] R.V. Rao, V.J. Savsani, D.P. Vakharia, "Teaching-learning-based optimization: A novel method for constrained mechanical 
design optimization problems", Computer-Aided Design, vol. 43, no 3, pp. 303-315, 2011.

[5] G.G. Tejani, V.J. Savsani, V.K. Patel, "Modified sub-population teachinglearning-based optimization for design of truss structures with natural frequency constraints" Mech. Based Des. Struc., vol. 44, no 4, pp. 495-513, 2016.

[6] M. Farshchin, C.V. Camp, M. Maniat, "Optimal design of truss structures for size and shape with frequency constraints using a collaborative optimization strategy", Expert Syst. Appl., vol. 66, pp. 203-18, 2016.

[7] A. Kaveh, A. Zolghadr, "Cyclical parthenogenesis algorithm for layout optimization of truss structures with frequency constraints", Eng. Optimiz., vol. 49, no 8, pp. 1317-1334, 2017.

[8] A. Kaveh, M.I. Ghazaan, "Vibrating Particles System Algorithm for Truss Optimization with Multiple Natural Frequency Constraints", Acta Mech., vol. 228, no 1, pp. 307-322, 2017.

[9] V. Ho-Huu, T. Nguyen-Thoi, T. TruongKhac, L. Le-Anh, T. Vo-Duy, "An improved differential evolution based on roulette wheel selection for shape and size optimization of truss structures with frequency constraints", Neural Comput. Appl., vol. 29, no. 1, pp.167-185, 2018.

[10]Q.X. Lieu, D.T.T, Do, J. Lee, “An adaptive hybrid evolutionary firefly algorithm for shape and size optimization of truss structures with frequency constraints", Comput. Struct., vol 195, pp. 99-112, 2018.

[11]A. Kaveh, M. Kooshkbaghi, "Enhanced artificial coronary circulation system algorithm for truss optimization with multiple natural frequency constraints", Period Polytech-Civ., vol. 63, no 2, pp. 362-376, 2019.
[12]A. Kaveh, S. Mahjoubi, "Hypotrochoid spiral optimization approach for sizing and layout optimization of truss structures with multiple frequency constraints", Eng. Comput., vol. 35, pp. 1443-1462, 2019.

[13]R.V. Rao, "Jaya: A simple and new optimization algorithm for solving constrained and unconstrained optimization problems", Int. J. Ind. Eng. Comput., vol. 7, pp. 19-34, 2016.

[14]R.V. Rao, K.C. More, J. Taler, P. Ocłon, "Dimensional optimization of a microchannel heat sink using Jaya algorithm", Appl. Therm. Eng., vol. 103, pp. 572-582, 2016.

[15] S.P. Singh, T. Prakash, V.P. Singh, M.G. Babu, "Analytic hierarchy process based automatic generation control of multi-area interconnected power system using Jaya algorithm”, Eng. Appl. Artif. Intel., vol. 60, pp. 35-44, 2017.

[16] S.O. Degertekin, L. Lamberti, I.B. Ugur, "Sizing, layout and topology design optimization of truss structures using the Jaya algorithm", Appl. Soft. Comput, vol. 70, pp. 903-928, 2018.

[17] S.O. Degertekin, L. Lamberti, I.B. Ugur, "Discrete sizing/layout/topology optimization of truss structures with an advanced Jaya algorithm", Appl. Soft. Comput, vol. 79, pp. 363-390, 2019.

[18] SAP 2000 v20. Integrated Software for Structural Analysis and Design. Computers \& Structures, Inc. Walnut Creek (CA), USA. 2018. 